Como citar: Coelho, E., da Silva, A., de Pellegrini, T., \& Patias, N. (2021). Saúde mental docente e intervenções da Psicologia durante a pandemia. PSI UNISC, 5(2), 20-32. doi: 10.17058/psiunisc.v5i2.16458

\title{
Saúde mental docente e intervenções da Psicologia durante a pandemia
}

\author{
Salud mental docente e intervenciones de la Psicología durante la pandemia
}

Teachers' mental health and Psychology interventions during the pandemic

\author{
Elenise Abreu Coelho \\ Universidade Federal de Santa Maria (UFSM), Santa Maria - RS/Brasil \\ ORCID: 0000-0002-5644-0668 \\ E-mail: elenise.ac@gmail.com
}

Ana Claudia Pinto da Silva

Universidade Federal de Santa Maria (UFSM), Santa Maria - RS/Brasil

ORCID: 0000-0002-2777-6023

E-mail: anaclaudiaps14@hotmail.com

Tais Barcellos de Pellegrini

Universidade Federal de Santa Maria (UFSM), Santa Maria - RS/Brasil

ORCID: 0000-0002-4121-174X

E-mail: taisbpellegrini@gmail.com

Naiana Dapieve Patias

Universidade Federal de Santa Maria (UFSM), Santa Maria - RS/Brasil

ORCID: 0000-0001-9285-9602

E-mail: naipatias@hotmail.com

\begin{abstract}
Resumo
Este estudo relata duas ações denominadas "Rodas de Conversa", desenvolvidas a partir de projeto de extensão em andamento, com ênfase na promoção de saúde mental docente durante a pandemia da Covid-19. As rodas on-line foram realizadas em duas escolas de ensino fundamental, uma pública e outra privada, de duas cidades do Rio Grande do Sul. Os relatos dos(as) docentes foram registrados em diário de campo e analisados conforme as três etapas do processo de análise de conteúdo categorial temática de Bardin. A análise resultou em três categorias e a sua interpretação baseou-se na literatura publicada até o momento sobre Covid-19, trabalho docente e saúde mental. Os resultados apontam dificuldades dos(as) docentes com relação à configuração de ensino remoto, sobrecarga pela intensificação do trabalho e relatos de sintomas de ansiedade e estresse. Com relação às ações do projeto, destaca-se a importância de espaços de acolhimento e escuta das demandas docentes. Salienta-se a necessidade de intervenções que visem à prevenção e a promoção de saúde mental dos(as) professores(as), principalmente nesse contexto.
\end{abstract}

Palavras-chaves: Docentes; Trabalho; Saúde mental; Pandemia; Psicologia.

\section{Resumen}

La Psicodinámica del Trabajo, abordaje teórico de este Este estudio reporta dos acciones denominadas "Rondas de Conversación", desarrolladas a partir de un proyecto de extensión en curso, con énfasis en promover la salud mental de docentes durante la pandemia de Covid-19. Las rondas en línea se realizaron en dos escuelas primarias, una pública y otra privada, de dos ciudades de Rio Grande do Sul. Los informes de los(as) docentes fueron registrados en un diario de campo y analizados conforme a las tres etapas del proceso de análisis de contenido categorial temático de Bardin. Los resultados fueron clasificados en tres categorías y su interpretación basada en la literatura publicada hasta el momento sobre Covid-19, trabajo docente y salud mental. Los resultados señalan dificultades de $\operatorname{los}$ (as) docentes respecto a la configuración de la enseñanza a distancia, sobrecarga por intensificación del trabajo e informes de síntomas de ansiedad y estrés. En cuanto a las acciones del proyecto, se destaca la importancia de espacios de acogida y escucha de las demandas docentes. Enfatizamos la necesidad de intervenciones dirigidas a prevenir y promover la salud mental de los(as) docentes, especialmente en dicho contexto. 
Palabras clave: Docentes; Trabajo; Salud mental; Pandemia; Psicología.

\begin{abstract}
This study aimed at reporting two actions called "Rounds of Conversation", developed from an ongoing extension project, with an emphasis on promoting teachers' mental health during the Covid-19 pandemic. The online rounds took place in two elementary schools, one public and one private, from two cities in the Rio Grande do Sul. The teachers' reports were recorded in a field diary and analyzed according to Bardin three-step process of category analysis of content. The analysis indicated three
\end{abstract}

categories and their interpretation was based on the literature published so far about Covid-19, teaching work, and mental health. The results point out difficulties of the teachers concerning the configuration of remote teaching, overload due to the intensification of work, and reports of symptoms of anxiety and stress. Regarding the actions of the project, the importance of welcoming spaces and listening to teaching demands are highlighted. Emphasis is placed on the need for interventions aimed at preventing and promoting mental health among teachers, especially in this context.

Keywords: Teachers; Work; Mental health; Pandemic; Psychology.

\section{Introdução}

A pandemia do novo coronavírus (Severe Acute Respiratory Syndrome Coronavirus 2 - SARS-Cov2) foi detectada inicialmente em Wuhan, na China, no final do ano de 2019 (Xiao, 2020). É considerada uma doença altamente contagiosa que se espalhou pelo mundo todo de forma muito rápida. Desse modo, foram instauradas medidas de prevenção e promoção à saúde da população, por meio do distanciamento social, para evitar a propagação do vírus da Covid-19. Tal medida acarretou inúmeras repercussões econômicas, sanitárias e sociais (Ventura, Aith, \& Rached, 2020).

Resultados de estudos nacionais e internacionais referem o impacto negativo da pandemia sobre a saúde mental da população em geral (Duarte, Santo, Lima, Giordani, \& Trentini, 2020; Valiente et al., 2021), pelo aumento de transtornos como o estresse póstraumático (TEPT), ansiedade, depressão, compulsão obsessiva, emoções negativas (raiva, estresse e tristeza), além de distúrbios no sono e na alimentação, aumento do consumo de substâncias psicoativas e maior preocupação com os membros da família (Cullen, Gulati, \& Kelly, 2020; Duarte et al., 2020; Freitas, Moura, Teixeira, Fernandes, \& Monteiro, 2021; Valiente et al., 2021).

As consequências relacionadas à pandemia têm sido devastadoras não apenas para a saúde mental, para a economia e, principalmente, para a educação no Brasil. No que diz respeito ao cenário educacional, houve a suspensão das atividades de ensino presencial em todos os níveis de formação, e a substituição pela modalidade remota. A pandemia da Covid19 trouxe a necessidade de uma reinvenção, recriação e readaptação do corpo docente, uma vez que existe uma demanda pela continuidade da educação de forma ativa para todos(as) os(as) estudantes, embora com discrepâncias entre o ensino público e privado no que tange a condição social e econômica dos(as) estudantes e docentes brasileiros(as).

A classe docente está vivenciando a intensificação das funções referentes ao seu trabalho. Há uma demanda constante das escolas, dos pais e/ou cuidadores e dos(as) próprios(as) estudantes. Pesquisas relatam a falta de privacidade, solicitações em horários (não comerciais) e dias (feriados, sábados e domingos) para sanar dúvidas, dentre outras necessidades. Esse contato é realizado de inúmeras formas como, por exemplo, ligações telefônicas, mensagens no WhatsApp e videochamadas (Branco \& Neves, 2020; Saraiva, Traversini, \& Lockmann, 2020).

Diante desse contexto, inúmeros desafios se apresentaram aos docentes que tiveram que organizar o espaço físico da casa para as aulas, realização de reuniões, treinamentos e cursos para o uso das tecnologias digitais (Nascimento, Souza, Milhomem, \& Macedo, 2020). Nesse sentido, surgiu a necessidade, sobretudo entre as mulheres, em conciliar o trabalho remoto, doméstico e em vários casos os cuidados dos(as) filhos(as) e/ou de seus pais idosos 
(Pereira, Santos, \& Manenti, 2020). Ademais, as atividades do lar, mesmo que compartilhadas com outras pessoas da família, pendura como responsabilidade atribuída naturalmente a pessoa do sexo feminino, mantendo-se assim uma desigualdade na divisão do trabalho, no diz respeito ao gênero no contexto brasileiro (Pessoa, Moura, \& Farias, 2021).

Percebe-se que o excesso de demandas criadas pela pandemia tem produzido sofrimento mental e emocional aos docentes. De fato, tem sido comum sentimentos de raiva, angústia, exaustão. Sintomas de estresse, ansiedade e depressão também têm sido frequentes nesse público, estando diretamente relacionados aos aspectos laborais e a situação de calamidade pública da pandemia (Oliveira, Balk, Graup, \& Muniz, 2020).

Diante do exposto, identifica-se a necessidade e importância de apresentar contribuições científicas para o campo da saúde mental, no que se refere às condições psíquicas dos(as) docentes em meio a esse momento atípico de pandemia. Assim, objetiva-se com este estudo relatar uma experiência de duas "Rodas de Conversa", desenvolvidas entre as ações de um projeto de extensão em andamento, com ênfase na promoção de saúde mental do(a) docente durante a pandemia da Covid-19.

\section{Método}

A proposta de intervenção relatada neste artigo originou-se de um projeto de pesquisa de dissertação em andamento, vinculado ao Programa de Pós-Graduação em Psicologia da Universidade Federal de Santa Maria, cujo público alvo são docentes da educação básica no Rio Grande do Sul, RS. Ao longo do processo de coleta de dados, observou-se a necessidade de ações que oportunizassem aos docentes um espaço de acolhimento e escuta sobre as dificuldades associadas ao contexto de trabalho na pandemia e as repercussões na saúde mental. Assim, foi elaborado o projeto de extensão "Trabalho e saúde mental dos professores durante e após a pandemia da COVID-19", que tem como principal objetivo realizar intervenções nas escolas, com foco na promoção de saúde mental docente. $\mathrm{O}$ projeto foi institucionalizado como ação extensionista junto a Universidade sob o número 055147, processo 23081.059400/2020-26.

As ações foram pensadas e organizadas em duas etapas: na primeira, que está sendo desenvolvida, são realizadas "Rodas de Conversa" nas escolas e divulgação de materiais psicoeducativos, com assuntos relacionados à saúde mental e ao contexto de trabalho docente na pandemia. Na segunda, propõe-se a realização de "Grupos com Professores", a partir de encontros temáticos estruturados com base nas principais demandas apontadas pelos(as) docentes. No presente artigo são relatadas duas ações da primeira etapa do projeto, que tiveram início em dezembro de 2020.

As "Rodas de Conversa" foram realizadas em duas escolas de ensino fundamental, uma da rede pública e outra da rede privada, de duas cidades interioranas no estado do Rio Grande do Sul. Os encontros aconteceram de forma on-line, via plataforma Google meet, com duração de 1 he $30 \mathrm{~min}$, em dias e horários previamente combinados com a direção das escolas. O tema abordado nas Rodas foi "Ser professor(a) durante a pandemia: desafios e possibilidades" e foram levantadas questões relacionadas às aulas remotas, os impactos na saúde mental e os aspectos percebidos como positivos pelos(as) docentes frente a esse cenário.

O contato com as escolas se deu mediante Carta de Apresentação do Projeto de Extensão, onde constavam todas as informações sobre os objetivos e a realização dos encontros. Também foi elaborado um folder informativo no formato de cartilha, que continha: a) a apresentação do grupo de pesquisa e os objetivos do projeto de extensão; b) breve justificativa sobre a relevância das ações do projeto; c) informações sobre os encontros, d) esclarecimento a respeito dos recursos necessários para a participação da escola ou do(a) docente, individualmente 
(celular ou dispositivo móvel com acesso à internet) e, e) informações de contato das pesquisadoras. Esse folder foi entregue junto à Carta de Apresentação para posteriormente ser repassado aos docentes. As Rodas foram oferecidas para cada escola em particular, a fim de promover um espaço confortável e sigiloso aos docentes. $\mathrm{O}$ contato com essas escolas se deu por meio de integrantes do grupo de pesquisa que possuíam contatos prévios com membros da equipe diretiva dos respectivos locais. Foi realizada uma reunião via grupo de WhatsApp com os representantes da direção das escolas, a fim de esclarecer sobre o projeto de Extensão e sensibilizar sobre a relevância das ações.

Com relação à operacionalização, na primeira escola, da rede pública, a roda foi realizada durante a semana de encerramento do calendário escolar, e participaram sete docentes mulheres de anos iniciais $\left(1^{\circ}\right.$ ao $5^{\circ}$ ano). $\mathrm{Na}$ segunda escola, da rede privada, a ação aconteceu na semana de formação dos(as) docentes, anterior ao retorno das aulas do ano letivo de 2021. Cabe salientar que essa escola havia obtido autorização e estava em processo de preparação dos protocolos sanitários para retomar as atividades presenciais. Os(as) docentes que tinham interesse e disponibilidade foram convidados a participar da Roda. A ação abrangeu os(as) docentes da educação infantil ao nono ano, totalizando cerca de 15 profissionais, sendo 12 mulheres e três homens. Em ambas as escolas foram informadas a ausência de alguns docentes, pois estavam no momento da "Roda de Conversa", trabalhando em outra escola.

No início dos encontros foi disponibilizado um link, via chat, que dava acesso ao Termo de Consentimento Livre e Esclarecido (TCLE), no qual manifestaram sua concordância em participar do projeto e tiveram assegurados o sigilo de sua identidade. Também foram realizadas as combinações referentes à dinâmica do encontro e uso da plataforma Google meet, como manter a câmera ligada e ativar o microfone somente nos momentos de fala para evitar interrupções.
Para iniciar as discussões, fez-se uso de uma apresentação em powerpoint com questões disparadoras relacionadas às temáticas do encontro. Essas questões consistiam em recortes de falas de docentes, retiradas de artigos, reportagens e matérias disponíveis na internet, como no exemplo a seguir:

\section{É um grande desafio lidar com minhas próprias emoções. Tenho medo que eu ou alguém da família adoeça e de não atender às demandas da escola, além de ansiedade por não saber até quando esse modelo de trabalho vai se estender e por não saber lidar tão bem com crianças no modelo remoto e com a apatia dos adolescentes. $O$ esgotamento é, praticamente, inevitável (Revista Quero, 2020).}

Após a leitura, os(as) docentes eram incentivados a compartilharem suas experiências. As "Rodas de Conversa" foram conduzidas pela mestranda responsável pelo desenvolvimento das ações do projeto, acompanhada de duas psicólogas integrantes do grupo de pesquisa.

Para registro das informações, foram utilizados diários de campo no qual foram descritas falas dos(as) docentes e impressões das psicólogas que realizaram as rodas. $\mathrm{O}$ material dos diários de campo foi submetido às três etapas da análise de conteúdo categorial temática (Bardin, 2016). Na primeira etapa, (a) pré-análise, foi realizada a leitura flutuante do conteúdo dos diários (corpus de análise). $\mathrm{Na}$ segunda etapa, (b) exploração do material, foram escolhidas as frases e trechos dos diários de campo agrupados em núcleos de sentidos (três categorias/temas) a partir dos objetivos e referenciais teóricos de pesquisas sobre as implicações da pandemia no trabalho docente (Oliveira \& Júnior, 2020; Souza et al., 2020; Pereira, Santos, \& Manenti, 2020): 1) adaptação às aulas remotas e relação famíliaescola; 2) transformação do domicílio em espaço de trabalho e relação trabalho-família; e, 3) implicações na saúde mental e recursos adotadas pelos(as) docentes. Por fim, na terceira etapa da análise de conteúdo categorial 
temática, (c) análise e interpretação dos dados, as três categorias foram analisadas e interpretadas (Bardin, 2016) com base em estudos prévios sobre o tema publicados até o presente momento (abril de 2021). A interpretação dos resultados se deu com base na literatura sobre a Covid-19, trabalho docente e saúde mental. Em relação à identificação dos participantes, optou-se por apresentar as falas de modo geral, com o intuito de preservar o sigilo das escolas e dos(as) respectivos(as) docentes.

O projeto de pesquisa ao qual se vinculam as ações extensionistas descritas neste artigo está de acordo com as Diretrizes e Normas Regulamentadoras de Pesquisas Envolvendo Seres Humanos, conforme as resoluções CNS n. ${ }^{\circ}$ 466/2012 e CNS n. ${ }^{\circ}$ 510/2016 e foi aprovado pelo Comitê de Ética em Pesquisa da Universidade Federal de Santa Maria, sob parecer de aprovação número 4.218.384.

\section{Resultados e discussão}

Os resultados são apresentados e discutidos a partir dos relatos dos(as) docentes em cada categoria temática:

\section{a) Adaptação às aulas remotas e a relação família-escola}

Nessa categoria são abordados aspectos relacionados aos processos de mudança das aulas presenciais para a modalidade remota, a adaptação às plataformas digitais e a relação das famílias com a escola. Sobre isso, os principais apontamentos dos(as) docentes foram com relação às aulas virtuais, embora não tenham apresentado dificuldades na adaptação do uso das plataformas on-line, relataram desconforto com as aulas gravadas pela questão da exposição às câmeras, conforme os relatos:

Às vezes tu começa a gravar uma vídeo aula e aí quando tu está finalizando o cachorro late, passa um carro de som na rua... e aí tu precisa parar e gravar tudo de novo". Nesse mesmo sentido, outra professora salienta: "Eu tenho muita facilidade de falar com uma multidão de pessoas, mas falar para uma câmera foi muito difícil pra mim, porque é diferente, tu não sabe como as pessoas estão recebendo o que tu está falando.

Outro aspecto levantado foi à exposição às famílias dos(as) alunos(as) nas aulas on-line, conforme relato:

Tu não está mais dando aula para o teu aluno, tu está ali dando aula para o aluno e a família dele, e os pais te avaliam, tu fica preocupado. Às vezes na sala de aula a gente faz uma brincadeira, uma gracinha, mas tu não sabe como isso vai ser interpretado em casa pelos pais.

Estudos anteriores realizados com docentes indicam que a modalidade on-line de ensino trouxe consigo inúmeros desafios, pois muitos docentes tiveram que, em poucas semanas, aprender a usar os diversos dispositivos eletrônicos, gravar as aulas e adaptar os conteúdos para serem transmitidos por meio de uma tela. Também há casos em que os pais e/ou cuidadores acompanham as aulas, especialmente dos(as) estudantes que estão nos anos iniciais (Guedes \& Santos, 2020; Silva, Andrade, \& Santos, 2020).

Nos relatos das rodas de conversa, foram observadas diferenças entre as vivências dos(as) docentes do ensino público e privado no que se refere a participação dos(as) estudantes e a relação família-escola. Por exemplo, as docentes da rede pública evidenciam as dificuldades de acesso dos estudantes às aulas on-line.

Estou presenciando várias dificuldades, pois muitos estudantes não possuem acesso a dispositivos eletrônicos ou às vezes quando possuem é apenas um, no qual há necessidade de compartilhar com os outros irmãos ou familiares. Não tive experiências positivas, pouca adesão 
mesmo, me sinto impotente $e$ frustrada.

Conforme o estudo de Gomes e Costa (2020) o cenário pandêmico intensifica as disparidades existentes no interior das escolas, principalmente nas instituições públicas, nas quais há expressiva redução de acesso a dispositivos eletrônicos (computador, tablet, smartphone) e internet. Esses aspectos indicam as disparidades sociais e econômicas na desigualdade do acesso a recursos mínimos para estudar de maneira não presencial, indicando uma preocupação legítima, por parte dos(as) docentes, no que diz respeito ao processo de ensino-aprendizagem em contexto de pandemia.

Além das preocupações socioeconômicas que impedem o acesso dos(as) estudantes, os(as) docentes referem dificuldades de acesso às famílias $\operatorname{dos}($ as $)$ estudantes: “(...) esse momento traz consigo muitos desafios, pois é uma busca constante de resgate dos alunos, por meio de ligações para os pais, mas muitos não atendem, por que mudaram de número ou até mesmo de endereço". Cabe salientar que a relação escolafamília apresenta um padrão bastante amplo, complexo e, sobretudo, influenciado por inúmeros fatores (Saraiva-Junges \& Wagner, 2016).

No relato dos(as) docentes da escola privada, percebe-se a alta exigência das famílias dos(as) estudantes em relação às atividades escolares e a organização da escola nesse contexto remoto:

Uma coisa que eu vejo é que é muito difícil contar com a colaboração dos pais. Os pais às vezes parecem que não entendem que a gente está fazendo o nosso melhor, estão sempre exigindo e exigindo porque pagam. Parece que não tem uma compreensão com esse momento.

Contudo, também relatam que esse contexto permitiu conhecer mais de perto a realidade do dia-a-dia das famílias dos(as) estudantes:

Eu acho que a vantagem foi que a gente também pôde conhecer a família dos nossos estudantes. Porque às vezes a gente não entende $e$ até interpreta o comportamento de um aluno de forma equivocada, quando a gente entra na casa dele e vê como são as relações da família, a gente entende muita coisa.

Esse dado corrobora o resultado de uma pesquisa realizada pela Fundação Carlos Chagas com 14.285 professores de 27 unidades escolares públicas e privadas do país no período de abril a maio de 2020. Ao verificar como os(as) professores estavam desenvolvendo suas atividades escolares de forma remota, pôde-se constatar uma melhoria de $45,6 \%$ na relação escola-família, pela participação mais ativa dos pais e/ou cuidadores na vida escolar dos(as) filhos(as) (Novaes et al., 2020). Assim, entende-se que a relação família-escola teve uma aproximação importante que tende a proporcionar evolução no processo de ensinoaprendizagem como um todo.

Os relatos permitem identificar que a mudança das aulas presenciais para a modalidade remota foi permeada por inúmeros desafios, principalmente porque não houve tempo hábil para organização e preparo, tanto das escolas quanto das famílias $\operatorname{dos}(\mathrm{as})$ estudantes. Além dos aspectos referentes às aulas, também foi necessário um processo de adaptação e reorganização na vida pessoal e familiar dos(as) docentes, já que o espaço de trabalho foi transposto para o domicílio. Alguns desses desafios são discutidos na próxima categoria.

\section{b) Transformação do domicílio em espaço de trabalho e relação trabalho-família}

Essa categoria diz respeito à transposição do espaço de trabalho dos(as) docentes para o domicílio. Cabe esclarecer que 
o espaço de trabalho inclui fatores para além do ambiente físico, como os recursos e materiais para viabilizar as aulas, planejamento, correções, avaliações, adaptação de conteúdos. Dessa forma, nessa categoria, são abordados aspectos relacionados à rotina de trabalho com a rotina doméstica e os impactos, na percepção de docentes, na relação trabalho-família durante a pandemia da Covid-19.

Entre os principais desafios relatados, estão as dificuldades em conciliar as atividades de trabalho na relação com a família, pois no relato de alguns(as) docentes, há outros membros do núcleo familiar que se encontram em trabalho remoto, sendo difícil haver delimitação clara entre o espaço físico de trabalho, de descanso e de lazer em família. A respeito disso, as docentes relatam a intensificação de tarefas com a pandemia, as quais ultrapassam sobremaneira a carga horária realizada em atividade presencial, já que há, com as redes sociais, o sentimento de que devem estar sempre à disposição da escola, dos(as) estudantes e de suas famílias. O celular pessoal passou a ser uma ferramenta de trabalho, impossibilitando os limites entre trabalho e vida privada, entre horário comercial e de descanso havendo uma disponibilidade irrestrita para o atendimento aos estudantes e seus familiares, na tentativa de suprir todas as demandas (Saraiva et al., 2020). Sobre esses aspectos, as docentes relatam: "Já aconteceu uma situação de eu responder a mãe de um aluno à meia noite, e eu não consigo olhar $e$ não responder." Outra docente refere:

A gente não consegue desligar, não tem aquela separação... Agora estou no meu trabalho, na sala de aula, depois chego em casa no meu ambiente de descanso. Eu montei um escritório aqui no meu quarto, comprei um quadro, está tudo aqui. Então parece que estou sempre ativo, à disposição do meu trabalho.

A sobrecarga pelo volume de trabalho é um dado relatado pela literatura muito antes do contexto da pandemia. O trabalho docente não se resume somente a sala de aula, envolve planejamento, leituras, elaboração de conteúdo, correção de materiais, elaboração de avaliações e pareceres, relatórios, reuniões pedagógicas, dentre outras atribuições (Carlotto \& Câmara, 2007; Ribeiro et al., 2012). Contudo, no contexto de trabalho remoto, somam-se outras atividades, além da necessidade de desenvolvimento de habilidades e recursos necessários para possibilitar as aulas remotas. Em muitos casos, essa transformação do espaço doméstico em local de trabalho ficou a cargo dos(as) próprios(as) docentes (Santos et al., 2020).

No relato das docentes, a sobrecarga tem sido maior, pois ainda são as principais cuidadoras e responsáveis pelos(as) filhos(as), pelo cuidado de familiares idosos e pelo trabalho doméstico. Muitas docentes relataram que as aulas remotas dos(as) filhos(as) têm exigido maior atenção e dedicação:

Para mim foi bem difícil, porque eu tenho um filho pequeno que precisa de mim para tudo. Ele também não estava indo para a escolinha, então como eu estava em casa, ele achava que eu estava ali disponível para ele." “(...) Além das demandas da escola, dos alunos e dos pais elou cuidadores destes alunos, tenho minha mãe que reside comigo, ela é idosa e depende muito do meu auxílio.

Vale salientar que a literatura aponta que famílias com crianças, com pessoas idosas que precisam de cuidado e, principalmente, em configuração monoparental, a conciliação entre o trabalho remoto e o doméstico tornou-se ainda mais desafiadora durante a pandemia (Oliveira, 2020) pelo acúmulo de funções. Embora tenha afetado significativamente a qualidade de vida das pessoas em geral, percebe-se que principalmente para as mulheres, o trabalho remoto provocou um acúmulo de tarefas, aumento das horas semanais dedicadas ao trabalho doméstico e cuidado de familiares, e redução no tempo investido para lazer e cuidado de si (Macêdo, 2020; Pessoa et al., 2021). Isso porque, mesmo antes da pandemia, as jornadas duplas ou triplas 
de trabalho já eram uma realidade enfrentada pelas mulheres que conciliavam vida profissional, maternidade e os cuidados da casa.

Esses dados permitem verificar que além da intensificação do trabalho, a pandemia trouxe uma série de outros agravos, tendo evidenciado as disparidades nos papéis atribuídos entre homens e mulheres. Assim, torna-se importante compreender as repercussões na saúde mental e os aspectos que auxiliaram os(as) docentes no enfrentamento desse ano atípico e desafiador, principalmente entre as mulheres, que fazem parte de aproximadamente $80 \%$ do corpo docente da educação básica no país (Carvalho, 2018). Algumas das implicações e recursos adotados pelos(as) docentes são descritos e discutidos na próxima categoria.

\section{c) Implicações na saúde mental e recursos adotados pelos(as) docentes}

Essa categoria aborda, as implicações da pandemia e do trabalho remoto na saúde mental dos(as) docentes. Também são relatados aspectos que perceberam como positivos e que têm auxiliado no momento de pandemia.

A nova configuração de trabalho remoto somada ao cenário de pandemia caracteriza-se pela intensificação da jornada, sobrecarga de trabalho e exigências que acabam por causar sofrimento aos docentes. Sobre esse aspecto, têm sido comuns os relatos de cansaço e sintomas de ansiedade, que favorecem o aumento no número de transtornos mentais entre esses profissionais (Souza et al., 2020). Esses aspectos surgiram nas rodas de conversa, como pode ser observado nos relatos: "Estou trabalhando 15 horas por dia ou até mais, isso é bem desgastante psiquicamente (...) passei a tomar medicação para ansiedade. (...) quase "surtei", pois queria abraçar o mundo". "A partir do contexto pandêmico passei a tomar medicação para controlar minhas crises de ansiedade".

A situação pandêmica associada às medidas de distanciamento social está relacionada ao aumento da prevalência de transtornos ansiosos e depressão. Um estudo realizado na China, logo após o surgimento da pandemia da Covid-19, mostrou que $40 \%$ dos participantes foram considerados propensos a problemas psicológicos e $14 \%$ da amostra com sintomas de estresse pós-traumático (Liang et al., 2020). No Brasil, por meio de um estudo transversal, foram analisadas a frequência de sentimentos de tristeza, nervosismo e alteração de sono entre 45.161 adultos e idosos durante o período de abril e maio de 2020. Contatou-se que $40,4 \%$ dos participantes relataram ter sentimento de tristeza, 52,6\% sintomas de ansiedade $52,6 \%$ e $48 \%$ problemas de sono (Barros et al., 2020). O estudo refere atenção especial desses sintomas em adultos jovens, mulheres e pessoas com histórico prévio de transtorno depressivo maior. Nesta perspectiva, considera-se que o impacto do distanciamento social aliado às exigências profissionais e às diversas demandas que foram criadas com a pandemia, têm produzido ou intensificado sintomas de transtornos mentais em docentes.

Apesar disso, os(as) docentes mencionaram alguns recursos e estratégias que têm sido úteis para enfrentar esse período de pandemia e a multiplicidade de tarefas somadas à sobrecarga de trabalho. Em relação aos recursos em aula, alguns(as) docentes relataram que a internet facilitou o acesso aos diversos conteúdos, antes pouco explorados nas aulas presenciais, conforme o seguinte relato:

Sou professor de geografia. Agora, quando eu vou falar de um país para meus alunos, eu abro o google e levo eles lá, tenho isso à minha disposição. Eu acho que isso é uma coisa que tem que ficar, é uma ferramenta muito importante.

Uma docente que ministra a disciplina de artes, relata que passou a perceber maior engajamento dos(as) estudantes frente a produção de materiais artísticos enviados no formato digital:

Atualmente os alunos estão super engajados, os desenhos que viravam 
aviõezinhos, hoje recebo de forma online em torno de $98 \%$ dos trabalhos. Com isso percebo mais reconhecimento em meu trabalho, então as partes boas das aulas remotas precisam ser ressaltadas.

Sobre a utilização de recursos diversificados como estratégias de ensinoaprendizagem, uma pesquisa nacional realizada em abril de 2020, revela que, para os 123 docentes investigados, há a percepção de novas oportunidades frente à utilização de variadas tecnologias digitais (TD). Segundo os(as) docentes da pesquisa, as TD são essenciais para a comunicação em reuniões on-line ou para videoconferências com todos os envolvidos no processo educacional (estudantes, coordenadores pedagógicos, equipe diretiva, monitores, pais e/ou cuidadores dentre outros). Da mesma forma, salientaram que a utilização das TD no processo de ensino, oportunizou aulas diferenciadas para os(as) estudantes (Rocha, Loss, Almeida, Motta, \& Kalinke, 2020).

Além das oportunidades e possibilidades de acesso a diferentes formas de ensino-aprendizagem, os relatos dos(as) docentes da rede pública e privada referem outro aspecto essencial, o reconhecimento recebido principalmente pelas famílias dos(as) estudantes e pela sociedade em geral: "Eu acho que a gente nunca foi tão reconhecido, eu acho que agora as pessoas estão vendo o nosso trabalho de verdade." "Mas ser professora é isso né, é se reinventar a todo momento. Se a gente não sabe, a gente vai lá e aprende para ensinar o nosso aluno."

Ainda, outra docente salienta: "Nesse cenário visualizo retornos positivos por parte das famílias, assim como a sociedade passou a valorizar o trabalho do professor". De fato, a pandemia da Covid-19 provocou uma série de impactos na sociedade, sendo que a educação foi uma das áreas que sofreu maiores consequências. No entanto, o cenário atual tem produzido reflexões sobre a educação no Brasil, incluindo uma maior valorização e reconhecimento ao trabalho docente (Barros \&
Vieira, 2021). Estes são os principais protagonistas do processo de ensinoaprendizagem de crianças, jovens e adultos.

No que diz respeito à realização das atividades do projeto de extensão, houve boa aceitação da proposta das "Rodas de Conversa" nas duas escolas. Ao final das rodas os(as) docentes agradeceram pela ação desenvolvida, destacando a importância de espaços de acolhimento e escuta de suas demandas. Também verbalizaram que, ao longo do ano, participaram de diversos momentos de reuniões e formações pedagógicas com o intuito de prepará-los(as) para o uso das plataformas digitais adotadas nas aulas remotas. Contudo, não tiveram espaços que possibilitassem a expressão de seus sentimentos, angústias e dificuldades associadas ao cenário da pandemia, avaliando a proposta do projeto como uma experiência positiva.

\section{Considerações finais}

O objetivo deste estudo foi relatar uma experiência de duas "Rodas de Conversa", desenvolvidas entre as ações de um projeto de extensão em andamento, com ênfase na promoção de saúde mental do(a) docente durante a pandemia da Covid-19. Essas ações foram realizadas em duas escolas, uma pública e uma privada, de duas cidades interioranas no RS. Os temas abordados foram relacionados às aulas remotas, os impactos na saúde mental e os recursos adotados pelos(as) docentes.

No geral, os relatos dos(as) docentes nas atividades realizadas indicam dificuldades em relação às aulas on-line, principalmente pela exposição às câmeras e aos ambientes virtuais. A sobrecarga e acúmulo de atividades docentes e domésticas, sobretudo entre as mulheres, é evidente, considerando que a divisão de tarefas não é vivenciada pela maioria das famílias. Dessa forma, as mulheres têm acumulado várias funções que poderiam produzir menor sofrimento se compartilhadas com o apoio de seus companheiros, maridos ou outros familiares. Foram percebidas diferenças no que diz respeito à educação pública e privada, principalmente 0 acesso às atividades 
síncronas, das aulas virtuais e materiais disponibilizados on-line. Estudantes e famílias de escolas públicas estão sofrendo maior exclusão com o advento da pandemia, sendo impedidos do direito à educação pela falta de condições básicas e pela necessidade de sobrevivência. Apesar destas dificuldades, os(as) docentes relatam o empenho em acessar famílias, buscando compreender a realidade de cada uma delas.

Sobre as implicações do trabalho remoto e da pandemia na saúde mental dos(as) docentes, é importante destacar os relatos frequentes de sintomas associados a transtornos mentais como ansiedade, depressão e estresse. Contudo, entre os fatores que têm auxiliado nas dificuldades, o reconhecimento, por parte das escolas, das famílias, estudantes e da sociedade como um todo, aparece como um importante balizador para continuar exercendo sua profissão.

$\mathrm{O}$ aceite das escolas em participar do projeto de extensão por meio das "Rodas de Conversa" são outros recursos importantes de valorização dos(as) docentes, possibilitando a escuta e o acolhimento por meio de profissionais de psicologia treinados. Observou-se essencial que docentes, se assim desejarem, tenham um espaço para o compartilhamento sobre o momento vivido, as funções que têm ocupado no trabalho, no ambiente doméstico e as estratégias utilizadas para o enfrentamento e exercício da profissão diante da falta de recursos, dos baixos salários e dos sintomas de transtornos mentais que têm acometido a classe.

Nesse sentido, sugerem-se novos trabalhos que tenham o intuito de promover ações como as do referido estudo, com ênfase na prevenção e promoção de saúde mental da classe docente. Soma-se a isso a necessidade de proporcionar melhores condições de trabalho, com oferta de qualificação às tecnologias de ensino, o bem-estar dos(as) docentes e a carga horária de trabalho, considerando que as horas ministradas de sala de aula são apenas uma das inúmeras atividades exercidas pelos(as) docentes e que o tempo e espaço da escola foi modificado por uma pandemia que colocou não apenas o Brasil, mas o mundo, em situação calamidade.

Como principal limitação do estudo, salienta-se o fato de que na escola pública participaram somente docentes (mulheres) dos anos iniciais ( $1^{\circ}$ ao $5^{\circ}$ ano), enquanto na escola privada participaram docentes (mulheres e homens) de todos os níveis (educação infantil ao $9^{\circ}$ ano). Além disso, não foi possível conhecer as percepções de toda a classe docente dos respectivos locais, pois alguns encontravam-se em atividade em outras escolas.

Por fim, salienta-se que a prática de extensão relatada neste estudo encontra-se em andamento. As ações iniciaram em dezembro de 2020, quando a primeira "Roda de Conversa" foi realizada, e logo foram interrompidas em função das férias escolares, sendo retomadas em fevereiro de 2021. Pretende-se dar continuidade às "Rodas de Conversa", bem como iniciar a ação de "Grupos com Professores" com encontros estruturados, os quais estão sendo organizados com base nas demandas levantadas pelos(as) docentes.

\section{Referências}

Bardin, L. (2016). Análise de conteúdo. São Paulo: Edições 70.

Barros, F. C., \& Vieira, D. A. da P (2021). Os desafios da educação no período de pandemia. Brazilian Journal of
Development, $\quad 7(1), \quad 826-849 . \quad$ doi: 10.34117/bjdv7n1-056

Barros, M. B. A., Lima, M. G., Malta, D. C., Szwarcwald, C. L., Azevedo, R. C. S., Romero, D., ... Gracie, R. (2020). Relato de tristeza/depressão, nervosismo/ansiedade e 
problemas de sono na população adulta brasileira durante a pandemia de COVID19. Epidemiologia e Serviços de Saúde, 29(4), 1-12. doi: 10.1590/s167949742020000400018

Branco, J. C. S., \& Neves, I. D. S. V. (2020). Trabalho docente em tempos de COVID-19: EaD e Educação Remota Emergencial. Educação, Ciência $e$ Cultura, 25(3), 19-33. doi: 10.18316/recc.v25i3.7382

Carlotto, M. S., \& Câmara, S. G. (2007). Preditores da Síndrome de Burnout em professores. Psicologia Escolar E Educacional, 11(1), 101-110. doi: 10.1590/S1413-85572007000100010

Carvalho, M. R. V. (2018). Perfil do professor da educação básica. Brasília, DF: Instituto Nacional de Estudos e Pesquisas Educacionais Anísio Teixeira, 2018. (Série Documental Relatos de Pesquisa, n. 41). Recuperado de: http://portal.inep.gov.br/documents/186968 1486324/Perfil+do+Professor+da+Educa\% C3\%A7\%C3\%A3o+B\%C3\%A1sica/6b636 752-855f-4402-b7d7b9a43ccffd3e?version $=1.13$

Cullen, W., Gulati, G., \& Kelly, B. D. (2020). Mental health in the Covid-19 pandemic. QJM: An International Journal of Medicine, 113(5), 311-312. doi: 10.1093/qjmed/hcaa110

Duarte, M. Q., Santo, M. A. S., Lima, C. P., Giordani, J. P., \& Trentini, C. M. (2020). Covid-19 and the impacts on mental health: a sample from Rio Grande do Sul, Brazil. Ciência \& Saúde Coletiva, 25(9), 3401-3411. doi: 10.1590/141381232020259.16472020

Freitas, R. J. M, Moura, N. A., Teixeira, L. A., Fernandes, A. P. N. L., \& Monteiro, A. R. M. (2021). Panorama das publicações em saúde mental no contexto da pandemia por COVID-19: scoping review. Global Academic Nursing Journal, 2(1), e84-e84. doi: 10.5935/2675-5602.20200084

Gomes, S. B., \& Costa, R. T. O. (2020). Engajamento dos alunos das escolas públicas em tempo de pandemia do coronavírus. IntegraEaD, 2(1), 11-11.
Recuperado

de:

https://trilhasdahistoria.ufms.br/index.php/I ntegraEaD/article/view/11788

Guedes, R. V., \& Santos, J. P. (2020). Formação de professores em tempos de pandemia. Projeção e Docência, 11(1), 01$25 . \quad$ Recuperado de: http://revista.faculdadeprojecao.edu.br/inde x.php/Projecao3/article/view/1603

Liang, L., Ren, H., Cao, R., Hu, Y., Qin, Z., Li, C., ... Mei, S. (2020). The Effect of COVID19 on Youth Mental Health. Psychiatric Quarterly. doi: 10.1007/s11126-020-09744$\underline{3}$

Macêdo, S. (2020). Ser mulher trabalhadora e mãe no contexto da pandemia Covid-19: tecendo sentidos. Rev. Nufen: Phenom. Interd., 12(2), 187-204. doi: 10.26823/RevistadoNUFEN.vol12.n ${ }^{\circ} 02$ rex. 33

Nascimento, L. R., Souza, J. M., Milhomem, M. S. F. S, \& Macedo, M. D. L. L. (2020). Psicologia e educação na promoção de bemestar psicossocial em tempos de pandemia: Relato de uma prática de extensão universitária. Capim Dourado: Diálogos em Extensão, 3(2), 47-69. doi: 10.20873/uft.2595-7341.2020v3n2p47

Novaes, A., Pagaime, A., Artes, A., Pimenta, C., Nunes, M., \& Gava, T. (2020). Educação escolar em tempos de pandemia. Fundação Carlos Chagas. Informe n. 1. Recuperado de: https://www.fcc.org.br/fcc/educacaopesquisa/educacao-escolar-em-tempos-depandemia-informe-n-1

Oliveira, A. L. (2020). A espacialidade aberta e relacional do lar: a arte de conciliar maternidade, trabalho doméstico e remoto na pandemia de COVID-19. Rev. Tamoios, 16(1), 154-166. doi: 10.12957/tamoios.2020.50448

Oliveira, D. A., \& Junior, E. A. P. (2020). Trabalho docente em tempos de pandemia: mais um retrato da desigualdade educacional brasileira. Revista Retratos da Escola, 14(30) 719-735. doi: $\underline{10.22420 / \text { rde.v14i30.1212 }}$ 
Oliveira, H. L. R., Balk, R. S., Graup, S., \& Muniz, A. G. (2020). Percepções sobre saúde mental de professores e professoras de uma escola pública da fronteira oeste do Rio Grande do Sul. Research, Society and Development, 9(4), e171943060e171943060. doi: $\underline{10.33448 / \text { rsd-v9i4.3060 }}$

Pereira, H. P., Santos, F. V., \& Manenti, M. A. (2020). Saúde mental de docentes em tempos de pandemia: os impactos das atividades remotas. Boletim de Conjutura, 3(9). Recuperado de: https://revista.ufrr.br/boca/article/view/Pere iraetal/3074

Pessoa, A. R. R., Moura, M. M. M., \& de Farias, I. M. S. (2021). A Composição do Tempo Social de Mulheres Professoras Durante a Pandemia. LICERE-Revista do Programa de Pós-graduação Interdisciplinar em Estudos do Lazer, 24(1), 161-194. doi: 10.35699/24476218.2021.29532

Revista Quero. (2020, dezembro 3). Desafios do ensino remoto impactam na saúde mental dos professores. [Página da Web] Recuperado de https://querobolsa.com.br/revista/desafiosdo-ensino-remoto-impactam-na-saudemental-dos-professores

Ribeiro, S. F. R., Martins, C. B. S., Mossini, F. C., Júnior, J. P., \& Lemos, L. C. V. (2012). Intervenção em uma Escola Estadual de Ensino Fundamental: Ênfase na Saúde Mental do Professor. Revista Mal-estar e Subjetividade, 12(3-4), 905-924. Recuperado de https://periodicos.unifor.br/rmes/article/vie w/5073/4078

Rocha, F. S. M., Loss, T., Almeida, B. L. C., Motta, M. S., \& Kalinke, M. A. (2020). O Uso de Tecnologias Digitais no Processo de Ensino durante a Pandemia da Covid-19. Interacções, 16(55), 58-82. doi: https://doi.org/10.25755/int.20703
Saraiva-Junges, L. A., \& Wagner, A. (2016). Os estudos sobre a relação família-escola no Brasil: uma revisão sistemática. Educação, 39(Esp), s114-s124. doi: 10.15448/19812582.2016.s.21333

Saraiva, K., Traversini, C., \& Lockmann, K. (2020). A educação em tempos de COVID 19: ensino remoto e exaustão docente. Práxis Educativa, 15, e2016289. doi: 10.5212/PraxEduc.v.15.16289.094

Silva, D. S., Andrade, L. A. P., \& Santos, S. M. P. (2020). Teaching alternatives in pandemic times. Research, Society and Development, 9(9), e424997177. doi:10.33448/rsd-v9i9.7177

Souza, K. R., Santos, G. B., Rodrigues, A. M. S., Félix, E. G., Gomes, L., Rocha, G. L., ... Peixoto, R. B. (2021). Trabalho remoto, saúde docente e greve virtual em cenário de pandemia. Trabalho, Educação e Saúde, 19, e00309141. doi: 10.1590/1981-7746sol00309

Valiente, C., Contreras, A. Peinado, V., Trucharte, A., Martinéz, A. P., \& Vázquez, C. (2021). Psychological adjustment in Spain during the COVID-19 pandemic: Positive and negative mental health outcomes in the general population. The Spanish Journal of Psychological, 24, 1-30. doi: 10.1017/SJP.2021.7

Ventura, D. D. F. L., Aith, F. M. A., \& Rached, D. H. (2020). The emergency of the new Coronavirus and the "Quarantine Law" in Brazil. Revista direito e praxis [Internet]. Preprint. doi: 10.1590/2179$\underline{8966 / 2020 / 49180}$

Xiao, C. (2020). A novel approach of consultation on 2019 novel coronavirus (COVID-19)-related psychological and mental problems: structured letter therapy. Psychiatry investigation, 17(2), 175. doi: 10.30773 / pi.2020.0047 


\section{Dados sobre os autores:}

- Elenise Abreu Coelho: Psicóloga (IMED), Mestranda em Psicologia pela Universidade Federal de Santa Maria (UFSM), Bolsista CAPES.

- Ana Claudia Pinto da Silva: Psicóloga (UFN), Mestranda em Psicologia pela Universidade Federal de Santa Maria (UFSM).

- Tais Barcellos de Pellegrini: Psicóloga, Mestre em Saúde Coletiva (UNISINOS), Doutoranda em Psicologia pela Universidade Federal de Santa Maria (UFSM).

- Naiana Dapieve Patias: Doutora em Psicologia (UFRGS), Professora do Departamento de Psicologia da Universidade Federal de Santa Maria (UFSM).

\section{Agradecimentos:}

- À Coordenação de Aperfeiçoamento de Pessoal de Nível Superior (CAPES) pela Bolsa, modalidade Demanda Social, da autora Elenise Abreu Coelho.

Declaração de Direito Autoral

A submissão de originais para este periódico implica na transferência, pelos autores, dos direitos de publicação impressa e digital. Os direitos autorais para os artigos publicados são do autor, com direitos do periódico sobre a primeira publicação. Os autores somente poderão utilizar os mesmos resultados em outras publicações indicando claramente este periódico como o meio da publicação original. Em virtude de sermos um periódico de acesso aberto, permite-se o uso gratuito dos artigos em aplicações educacionais e científicas desde que citada a fonte conforme a licença CC-BY da Creative Commons. 